\title{
Predictive Factors for Acute Esophageal Toxicity in Thoracic Radiotherapy
}

\author{
Ken Takeda, Kenji Nemoto, ${ }^{1}$ Haruo Saito, Yoshiniro Ogawa, ${ }^{1}$ Yoshiniro Takai ${ }^{2}$ \\ and SHOGO YAMADA ${ }^{1}$ \\ Department of Radiology, National Hospital Organization Sendai Medical \\ Center, Sendai, Japan, \\ ${ }^{1}$ Department of Radiation Oncology, Tohoku University School of Medicine, \\ Sendai, Japan, and \\ ${ }^{2}$ Department of Radiological Sciences, Course of Health Sciences, Tohoku \\ University School of Medicine, Sendai, Japan
}

Takeda, K., Nemoto, K., Saito, H., Ogawa, Y., Takai, Y. and Yamada, S. Predictive Factors for Acute Esophageal Toxicity in Thoracic Radiotherapy. Tohoku J. Exp. Med., 2006, 208 (4), 299-306 - Acute esophageal toxicity (AET) is a common complication and dose-limiting toxicity in thoracic radiotherapy. Previous studies demonstrated several clinical and dosimetric parameters of AET in patients with lung cancer. However, there are few reports dealing with these variables in intra-thoracic malignancies, including lung cancer and other thoracic malignancy. The purpose of this study was to evaluate the clinical and dosimetric factors associated with AET in patients with intra-thoracic malignancies. We examined 61 patients with intra-thoracic malignancies treated with radiotherapy: 34 patients with non-small-cell lung cancer (55\%), 9 cases with small-cell lung cancer (15\%), 7 cases with thymic cancer (11\%), 4 thymomas (7\%), 2 malignant lymphomas (3\%), one seminoma (2\%), one liposarcoma (2\%), and 3 cases of other malignancies (5\%). Radiotherapy was performed with a median dose of 60 Gray (Gy) (range 40-67 Gy). AET was graded according to the Radiation Therapy Oncology Group (RTOG) criteria. The following parameters were analyzed with respect to associations with AET by univariate and multivariate analyses: age, gender, thoracic surgery before radiotherapy, concurrent chemotherapy, duration of radiotherapy, maximum esophageal dose, mean esophageal dose, and percentage of esophageal volume receiving from $10 \mathrm{~Gy}$ (V10) to 65 Gy (V65), in 5-Gy increments. 43 patients (70\%) developed AET: 36 patients $(59 \%)$ with AET of RTOG Grade 1, 7 patients (11\%) with Grade 2, and no patients $(0 \%)$ with Grade 3 or worse. On multivariate analysis, V35 $>30 \%$ was the most statistically significant factor associated with mild AET ( $p=0.013$ ). Our findings provide a better understanding of the factors related to AET, and might be useful in designing a treatment plan to prevent severe esophageal toxicity. — acute esophageal toxicity; radiotherapy; predictions; thoracic neoplasms

(C) 2006 Tohoku University Medical Press

Received October 12, 2005; revision accepted for publication February 2, 2006.

Correspondence: Ken Takeda, Department of Radiology, National Hospital Organization Sendai Medical Center, 2-8-8 Miyagino, Miyagino-ku, Sendai 983-8520, Japan.

e-mail: takedak41@yahoo.co.jp 
Acute esophageal toxicity (AET) is known to be a significant dose-limiting toxicity (DLT) and one of the main complications of thoracic radiotherapy (TRT) given for lung cancer (Byhardt et al. 1998; Choy et al. 1999; Bruner et al. 2004).

Previous researches reported the following dosimetric predictors for AET: the percentage of esophageal volume receiving $>45$ Gy (V45), V50, V60; the length of the esophagus in the treatment field; the maximal esophageal point dose; hyper-fractionated radiotherapy; and the esophageal surface area receiving $\geqq 55$ Gy (A55) (Werner-Wasik et al. 2000; Hirota et al. 2001a; Singh et al. 2003; Bradley et al. 2004; Patel et al. 2004; Ahn et al. 2005; Kim et al. 2005). Most of these predictors were related to AET Radiation Therapy Oncology Group (RTOG) criteria grade 2-3 or worse (Cox et al. 1995). In contrast, our previous study indicated that V35 was a significant dosimetric predictor for AET of RTOG grade 1-2 (Takeda et al. 2005).

Several authors have noted significant toxicity not only in lung cancer patients, but also in patients with other intra-thoracic malignancy (Hirota et al. 2001b; Perez and Early 2002; Chen et al. 2004). However, there have been few reports dealing with dosimetric parameters for AET in patients with intra-thoracic malignancies, including both lung cancer and other thoracic malignancy treated with TRT. Thus, in the pres- ent study, we evaluated clinical and dosimetric parameters associated with AET in intra-thoracic malignancy patients receiving TRT.

\section{Materials and Methods}

\section{Patient characteristics}

Between February 2000 and April 2005, a total of 61 patients underwent TRT for lung cancer and other intra-thoracic malignancies at the National Hospital Organization Sendai Medical Center and Tohoku University Hospital in Sendai, Japan. All patients were hospitalized during treatment. To be included in this analysis, the 61 patients had to fulfill the following criteria: their charts, hospital computerized data, and radiotherapy datasets for calculation of dose-volume histograms (DVHs) had to be completed and readily available (Sailer 2000) (Fig. 1); they did not have pre-treatment dysphagia, anorexia, or ingestion difficulties; and they were not undergoing palliative treatment. Patient characteristics are shown in Table 1. The study population included 44 men and 17 women with a median age of 68 years (range 26-88 years). The 43 lung cancer patients' histological types were reported as: adenocarcinoma, 16 patients (26\%); squamous cell carcinoma, 13 patients (20\%); large cell carcinoma, 3 patients (5\%); spindle cell carcinoma, 1 patient (2\%); small-cell carcinoma, 9 patients (15\%); and not otherwise specified, 1 patient $(2 \%)$. Four patients $(6 \%)$ had stage I disease, $1(2 \%)$ had stage II, $10(17 \%)$ had stage IIIa, $11(18 \%)$ had stage IIIb, 13 (21\%) had stage IV, and $4(6 \%)$ were treated for recurrent disease after surgery. The histology of the

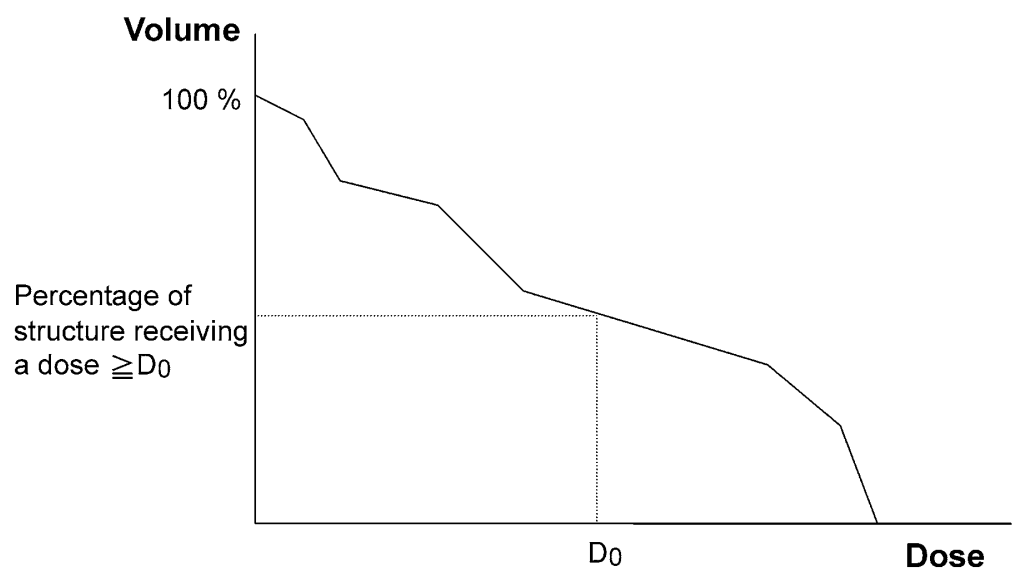

Fig. 1. Dose volume histogram.

The dose-volume histogram (DVH) is one of the fundamental tools used in plan evaluation. At any point on the curve, one is reading the percentage of a volume that receives a dose greater than or equal to the specified dose (Do). 
TABle 1. Patient characteristics $(n=61)$

\begin{tabular}{|c|c|c|c|}
\hline \multicolumn{3}{|c|}{ Characteristics } & \multirow{2}{*}{$\begin{array}{r}n(\%) \\
44(72)\end{array}$} \\
\hline \multirow{2}{*}{\multicolumn{2}{|c|}{ Gender }} & Men & \\
\hline & & Women & $17(28)$ \\
\hline \multirow{2}{*}{\multicolumn{2}{|c|}{ Age }} & Range & $26-88$ \\
\hline & & Median & 68 \\
\hline \multirow[t]{22}{*}{ Disease } & \multirow[t]{6}{*}{ Lung cancer } & Adenocarcinoma & $16(26)$ \\
\hline & & Squamous-cell carcinoma & $13(20)$ \\
\hline & & Large-cell carcinoma & $3(5)$ \\
\hline & & Spindle-cell carcinoma & $1(2)$ \\
\hline & & Small-cell carcinoma & $9(15)$ \\
\hline & & Not otherwise specified & $1(2)$ \\
\hline & \multirow[t]{6}{*}{ Stage } & I & $4(6)$ \\
\hline & & II & $1(2)$ \\
\hline & & IIIA & $10(17)$ \\
\hline & & IIIB & $11(18)$ \\
\hline & & IV & $13(21)$ \\
\hline & & Recurrence after surgery & $4(6)$ \\
\hline & \multirow[t]{10}{*}{ Other disease } & Invasive thymoma & $4(6)$ \\
\hline & & Thymic well-differentiated cancer & $6(8)$ \\
\hline & & Thymic undifferentiated cancer & $1(2)$ \\
\hline & & Heterotopic thyroid cancer & $1(2)$ \\
\hline & & Diffuse large B-cell lymphoma & $1(2)$ \\
\hline & & Hodgkin disease & $1(2)$ \\
\hline & & Seminoma & $1(2)$ \\
\hline & & Liposarcoma & $1(2)$ \\
\hline & & Undifferentiated cancer & $1(2)$ \\
\hline & & Metastatic adenocarcinoma & $1(2)$ \\
\hline
\end{tabular}

other diseases was: invasive thymoma, 4 patients $(6 \%)$; thymic well-differentiated cancer, 6 patients $(8 \%)$; thymic undifferentiated cancer, 1 patient $(2 \%)$; heterotopic thyroid papillary carcinoma, 1 patient (2\%); diffuse large B-cell type lymphoma, 1 patient (2\%); relapsed Hodgkin disease, 1 patient (2\%); seminoma, 1 patient (2\%); liposarcoma, 1 patient (2\%); undifferentiated cancer, 1 patient (2\%); and metastatic adenocarcinoma, 1 patient $(2 \%)$. According to the thymoma staging system of Masaoka et al. (1981), 1 thymoma patient (2\%) had stage II, $1(2 \%)$ had stage III, and $2(3 \%)$ had stage IV. Fifteen patients $(25 \%)$ underwent thoracic surgery before TRT: postoperative prophylactic TRT for lung cancer, 1 patient $(2 \%)$; invasive thymoma, 3 patients $(5 \%)$; thymic welldifferentiated cancer, 4 patients $(6 \%)$; heterotopic thyroid papillary carcinoma, 1 patient (2\%); seminoma, 1 patient
(2\%); liposarcoma, 1 patient (2\%); and postoperative recurrent lung cancer, 4 patients $(6 \%)$. We did not include esophageal cancer patients in this study, due to difficulties in evaluating AET in these patients based on clinical and dosimetric analyses. It is very difficult to contour when normal tissue must be distinguished from the malignant portion on computed tomograpy (CT) images in esophageal cancer patients. Furthermore, clinically it is often difficult to clearly determine whether symptoms are due to esophageal cancer or AET.

A total of 41 patients $(67 \%)$ were treated with concurrent chemoradiotherapy. The regimens of concurrent chemotherapy are summarized in Table 2. Carboplatin was administered at a dose equal to an area under the plasma concentration-time curve of 5-6 every 4 weeks for 2-3 consecutive cycles. Cisplatin $\left(45-80 \mathrm{mg} / \mathrm{m}^{2}\right)$ was 
TABLE 2. Summary of concurrent chemotherapy

\begin{tabular}{lc}
\hline $\begin{array}{l}\text { Chemotherapeutic agents combined } \\
\text { with cisplatin or carboplatin }\end{array}$ & $n(\%)$ \\
\hline Paclitaxel & $24(39)$ \\
Irinotecan hydrochloride & $7(11)$ \\
Vincristine sulfate and etoposide & $2(3)$ \\
Vinorelbine ditartrate & $1(2)$ \\
Etoposide & $5(8)$ \\
Vindesine sulfate and mitomycin C & $1(2)$ \\
Docetaxel & $1(2)$ \\
\hline
\end{tabular}

given every 3-4 weeks for 3 consecutive cycles. The dose and schedule for the administration of combined agents during the radiotherapy period were: paclitaxel $\left(50-70 \mathrm{mg} / \mathrm{m}^{2}\right)$ weekly for 3 weeks every 3-4 weeks for 2-3 cycles; irinotecan hydrochloride $\left(45-60 \mathrm{mg} / \mathrm{m}^{2}\right)$ weekly for 3 weeks every 4 weeks for 3 cycles; vincristine sulfate $\left(1.3 \mathrm{mg} / \mathrm{m}^{2}\right)$ every 4 weeks for $3-4$ cycles; etoposide $\left(60-100 \mathrm{mg} / \mathrm{m}^{2}\right)$ daily for 3 days every 4 weeks for 3-4 cycles; vinorelbine ditartrate $\left(10 \mathrm{mg} / \mathrm{m}^{2}\right)$ on days $1,8,22,29,36$, and 44 ; vindesine sulfate $\left(3 \mathrm{mg} / \mathrm{m}^{2}\right)$ on days $1,8,22,29,36$, and 44 ; mitomycin $\mathrm{C}\left(8 \mathrm{mg} / \mathrm{m}^{2}\right)$ every 3 weeks for 3 cycles; and docetaxel $\left(60 \mathrm{mg} / \mathrm{m}^{2}\right)$ every 3 weeks for 2 cycles.

\section{Treatment planning and treatment}

CT-based treatment planning was done in all patients with immobilization devices. Radio-opaque markers were placed on the patient's skin, and the immobilization device was used to assist in positioning.
The treatment planning for lung cancer patients was based on gross tumor volume (GTV) that included all the tumors and abnormally enlarged regional lymph nodes greater than $1 \mathrm{~cm}$ in diameter seen on CT images (International Commission on Radiation Units and Measurements 1993; Clifford et al. 2002) (Fig. 2). Clinical target volume (CTV) encompassed the GTV, as well as the mediastinal and ipsilateral pulmonary hilar lymph nodes that were regarded as having potential microscopic disease. Planning target volume (PTV) 1 included the CTV and a $1-1.5 \mathrm{~cm}$ margin. PTV2 involved the GTV and a $1 \mathrm{~cm}$ margin. Radiation was given through the anteroposterior-posteroanterior (APPA) portals for PTV1 up to 39.6-40 Gy, followed by offspinal cord oblique portals for PTV2 in a sequential manner. The treatment planning for patients with other diseases was based on GTV that included all the tumors or residual tumors after surgical resection. CTV included the GTV and a 1-1.5 $\mathrm{cm}$ margin, or preoperatively all of the tumors and a 1-2 cm margin. PTV encompassed the CTV and a respiratory movement margin. TRT was directed through the AP-PA portals followed by offspinal cord oblique portals for PTV sequentially, or twowedge portals (right and left anterior oblique) for PTV. TRT was delivered by linear accelerators with 4 MV, 6 $\mathrm{MV}$, or $10 \mathrm{MV} \mathrm{x}$-rays using single daily fractions of either $1.8 \mathrm{~Gy}$ or $2.0 \mathrm{~Gy}$. The dose to which the spinal cord was exposed was kept below $45 \mathrm{~Gy}$. The median prescription dose to the isocenter was 60 Gy (range 40-67 Gy). Dose calculations were performed to correct for lung in-homogeneity, using superposition algorithm. The median corrected dose for all patients was 60 Gy

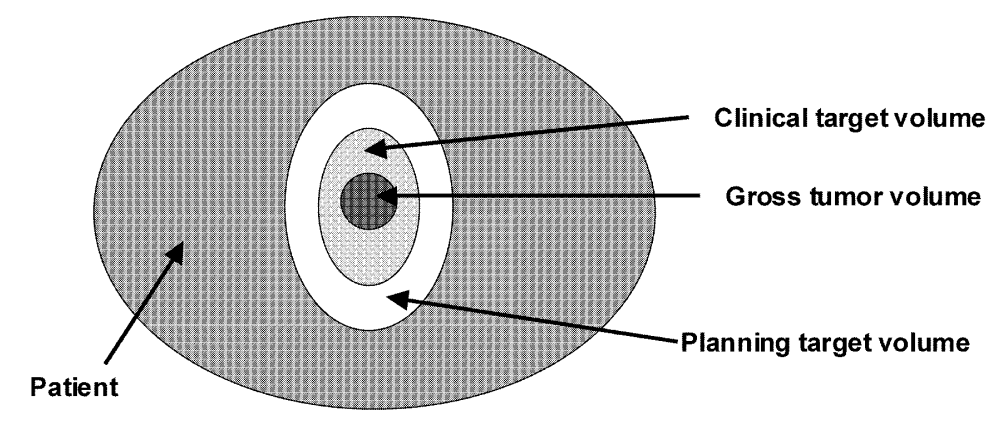

Fig. 2. Volumes of interest.

International Commission on Radiation Units and Measurements Reports No. 50 (ICRU 50) defines the following treatment planning volumes. Gross tumor volume (GTV) encompasses all known gross disease and abnormally enlarged regional lymph nodes. Clinical target volume (CTV) contains the GTV and regions considered to microscopic disease. Planning target volume (PTV) provides margin around CTV to allow for internal target motion, other anatomic motion during treatment, and variations in treatment setup. 
TABLE 3. RTOG scoring criteria for acute esophageal toxicity

\begin{tabular}{cl}
\hline Score & \\
\hline 0 & $\begin{array}{l}\text { No change over baseline } \\
\text { Mild dysphagia or odynophagia; may require topical anesthetic, nonnarcotic agents, } \\
\text { or soft diet }\end{array}$ \\
2 & $\begin{array}{l}\text { Moderate dysphagia or odynophagia; may require narcotic agents or puree/liquid diet } \\
\text { Severe dysphagia or odynophagia with dehydration or weight loss ( }>15 \%\end{array}$ \\
3 & $\begin{array}{l}\text { from pretreatment baseline) requiring nasogastric feeding tube, i.v. fluids, or } \\
\text { hypentation }\end{array}$ \\
& Complete obstruction, ulceration, perforation, or fistula \\
5 & Death
\end{tabular}

RTOG, Radiation Therapy Oncology Group.

(range 40-68 Gy).

\section{Follow-up and evaluation of AET}

The follow-up period for all patients was from 2 to 37 months, with a median of 8 months. At least once a week during the course of TRT, patients were evaluated and treated by a radiation oncologist for any complaints. After completion of treatment, patients were followed-up at one-month intervals during the first year and then every 3 to 6 months by their physicians. AET was graded according to RTOG criteria (Cox et al. 1995)(Table 3). The data used to grade the esophagitis reflected the worst grade of toxicity experienced by the patients.

\section{Acquisition of dosimetric data and statistical analysis}

The patients' treatment plans were analyzed retrospectively so as to determine the significant factors that could have been involved in causing AET. Our institutional committee did not require ethical approval for this retrospective study. The external surface of the esophagus was contoured uniformly on each $5 \mathrm{~mm}$ axial image of the planning CT scan from the level of the lower end of the cricoid cartilage to the gastroesophageal junction by one of the authors. DVHs and dose distributions for the esophagus were calculated. We analyzed the following dosimetric parameters: maximum esophageal dose (Dmax); mean esophageal dose (Dmean); and V10 to V65 in 5-Gy dose increments. Means, medians, and ranges of these parameters are shown in Table 4. Furthermore, we examined the correlation between AET and the following factors: age, gender, thoracic surgery before TRT, concurrent chemotherapy, chemotherapeutic agents, and overall TRT duration. These parameters were analyzed with respect to their relationship with
TABLE 4. Mean, median, and range of 14 dosimetric parameters

\begin{tabular}{lccr}
\hline \multicolumn{1}{c}{ Parameter } & Mean & Median & \multicolumn{1}{c}{ Range } \\
\hline Dmax (Gy) & 53.3 & 57.8 & $30.5-68.7$ \\
Dmean (Gy) & 17.7 & 17.0 & $1.9-37.1$ \\
V10 (\%) & 42.0 & 40.2 & $5.3-85.7$ \\
V15 (\%) & 39.8 & 37.1 & $3.5-83.8$ \\
V20 (\%) & 37.5 & 33.9 & $1.6-80.7$ \\
V25 (\%) & 35.2 & 33.7 & $0.6-76.1$ \\
V30 (\%) & 31.6 & 29.9 & $0.03-74.1$ \\
V35 (\%) & 28.4 & 28.3 & $0-70.9$ \\
V40 (\%) & 21.7 & 21.9 & $0-66.3$ \\
V45 (\%) & 15.8 & 11.7 & $0-59.3$ \\
V50 (\%) & 10.7 & 5.8 & $0-54.6$ \\
V55 (\%) & 7.3 & 1.0 & $0-42.0$ \\
V60 (\%) & 2.3 & 0 & $0-35.9$ \\
V65 (\%) & 0.3 & 0 & $0-10.7$ \\
\hline
\end{tabular}

Dmax, maximum esophageal dose; Dmean, mean esophageal dose; V10-V65, percentage of esophageal volume receiving 10 Gy to 65 Gy.

Grade 1 or greater esophagitis using Fisher's exact test (two-tailed), chi-square test (two-tailed), and Spearman rank correlation analysis (two-tailed). For multivariate analysis, the stepwise procedure was performed using a logistic regression method containing all variables that achieved univariate statistical significance. Statistical analyses were performed using SPSS (version 11.0 for Windows). Values of $p<0.05$ were considered statistically significant. 


\section{Results}

Forty-three of 61 patients (70\%) developed AET. The worst AET RTOG grades experienced by the patients were: Grade 1, 36 patients (59\%); Grade 2, 7 patients (11\%); Grade 3 or worse, 0 patients $(0 \%)$. In this study, all cases of AET developed during the TRT period, and the patients recovered from AET immediately after TRT completion. All patients had completed TRT without pause due to AET. None of the patients died within 1 month of TRT completion, and none developed severe dehydration.

There were no significant correlations with the following factors: age, $p=0.868$, correlation coefficient $=-0.022$ (Spearman's rank correlation); gender, $p=0.229$ (Fisher's exact test); thoracic surgery before TRT, $p=0.34$ (Fisher's exact test); concurrent chemotherapy, $p=0.242$ (Fisher's exact test); chemotherapeutic agents, $p=$ 0.259 (Pearson's chi-square test); and overall TRT duration, $p=0.244$, correlation coefficient $=0.151$

TABLE 5. Correlation between dosimetric parameters and esophagitis

\begin{tabular}{lcc}
\hline Parameter & Correlation coefficient & $p$ \\
\hline Dmax (Gy) & 0.226 & 0.080 \\
Dmean (Gy) & 0.342 & 0.007 \\
V10 (\%) & 0.297 & 0.020 \\
V15 (\%) & 0.301 & 0.018 \\
V20 (\%) & 0.309 & 0.016 \\
V25 (\%) & 0.304 & 0.017 \\
V30 (\%) & 0.370 & 0.003 \\
V35 (\%) & 0.419 & $0.001^{*}$ \\
V40 (\%) & 0.405 & 0.001 \\
V45 (\%) & 0.357 & 0.005 \\
V50 (\%) & 0.333 & 0.009 \\
V55 (\%) & 0.259 & 0.044 \\
V60 (\%) & 0.134 & 0.304 \\
V65 (\%) & -0.047 & 0.718 \\
\hline
\end{tabular}

Dmax, maximum esophageal dose; Dmean, mean esophageal dose; V10-V65, percentage of esophageal volume receiving $10 \mathrm{~Gy}$ to $65 \mathrm{~Gy}$.

${ }^{*}$ Highest statistical significance.
(Spearman's rank correlation).

Table 5 shows the results of Spearman's rank correlation for Dmean and V10-V55 to predict AET. On logistic regression analysis, the most statistically significant predictor of AET is V35 $(p=0.020)$. AET developed in 18 of 32 patients $(56.3 \%)$ with $\mathrm{V} 35 \leqq 30 \%$ and in 25 of 29 patients (86.2\%) with V35 > 30\%, $p=0.013$ (Fisher's exact test, two tail). AET developed in 6 of 14 patients $(42.9 \%)$ with $\mathrm{V} 35 \leqq 15 \%$ and in 37 of 47 patients $(78.7 \%)$ with V35 $>15 \%, p=0.018$ (Fisher's exact test, two tail). Furthermore, AET developed in 17 of 44 patients $(38.6 \%)$ with V35 $\leqq 40 \%$ and in 16 of 17 patients $(94.1 \%)$ with V35 $>40 \%, p=0.013$ (Fisher's exact test, two tail). On logistic regression analysis, V35 > 30\% was the most significant factor $(p=0.013)$.

\section{Discussion}

Previous studies have identified several clinical and dosimetric factors that are related to radiation-induced esophageal toxicity (ET) in patients with lung cancer (Werner-Wasik et al. 2000; Hirota et al. 2001a; Singh et al. 2003; Bradley et al. 2004; Patel et al. 2004; Ahn et al. 2005; Kim et al. 2005; Takeda et al. 2005) (Table 6). However, there have been few studies that have examined these factors for ET in patients with other thoracic malignancies, though several authors have reported on ET in patients with intra-thoracic malignancies (Hirota et al. 2001b; Perez et al. 2002; Chen et al. 2004). According to Chen et al. (2004), Grade 1-2 esophagitis was one of the most common side effects in concurrent chemoradiotherapy for thymic carcinoma. AET occurs not only in lung cancer patients, but also in patients with other intra-thoracic malignancies patients receiving TRT. Therefore, in the present study, we investigated the clinical and dosimetric factors of AET in intra-thoracic malignancies including both lung cancer and other intra-thoracic malignancies.

As shown in Table 6, although most of previous studies indicated parameters of AET of RTOG grade 2 or worse, there are few reports about AET of RTOG grade 2 or less. However, according to previous publications, the incidence of AET of RTOG grade 1 in lung cancer patients is higher 
TABLE 6. Literature review: dose of radiotherapy and dosimetric predictive factors for acute esophageal toxicity

\begin{tabular}{|c|c|c|c|}
\hline Study & Dose of radiotherapy & Endpoint & Factors \\
\hline $\begin{array}{l}\text { Werner-Wasik et al. } \\
(2000)\end{array}$ & $\begin{array}{l}45-69.6 \mathrm{~Gy} \text { (median, } 59.9 \mathrm{~Gy} \text { ) } \\
98 \text { patients with once daily fractions } \\
7 \text { patients with twice daily fractions }\end{array}$ & $\begin{array}{l}\text { Esophagitis index } \\
\text { Maximum grade* }\end{array}$ & $\begin{array}{l}\text { CCT } \\
\text { CCT, b.i.d RT }\end{array}$ \\
\hline Hirota et al. (2001a) & $\begin{array}{l}50-60 \mathrm{~Gy} \\
\text { Single daily fractions of } 2 \mathrm{~Gy}\end{array}$ & Grade 2 or worse & LETT45, V45 \\
\hline Singh et al. (2003) & $\begin{array}{l}60-74 \mathrm{~Gy} \text { (median, } 70 \mathrm{~Gy} \text { ) } \\
\text { Single daily fractions of } 2 \mathrm{~Gy}\end{array}$ & Grade 3 or worse ${ }^{*}$ & Maximal dose $\geqq 58$ Gy, CCT \\
\hline Bradley et al. (2004) & $\begin{array}{l}60-74 \text { Gy (median, } 70 \mathrm{~Gy} \text { ) } \\
\text { Single daily fractions of } 1.8-2.1 \mathrm{~Gy}\end{array}$ & Grade 2 or worse ${ }^{*}$ & A55, V60, CCT \\
\hline Patel et al. (2004) & $\begin{array}{l}69.6 \mathrm{~Gy} \\
\text { Twice daily fractions of } 1.2 \mathrm{~Gy}\end{array}$ & Grade 2 or worse* & BMI, V50 \\
\hline Ahn et al. (2005) & $\begin{array}{l}30-86.4 \text { Gy (median, } 66 \mathrm{~Gy} \text { ) } \\
156 \text { patients with once daily fractions } \\
98 \text { patients with twice daily fractions }\end{array}$ & $\begin{array}{l}\text { Grade } 2 \text { or worse* } \\
\text { Grade } 3 \text { or worse* }\end{array}$ & $\begin{array}{l}\text { Twice daily RT, N stage, age, } \\
\text { maximal point dose } \\
\text { Twice daily RT, N stage, } \\
\text { pre-RT dysphagia }\end{array}$ \\
\hline Kim et al. (2005) & $\begin{array}{l}54-66 \mathrm{~Gy} \text { (median, } 60 \mathrm{~Gy} \text { ) } \\
\text { Single daily fractions of } 2 \mathrm{~Gy}\end{array}$ & Grade 3 or worse* & $\mathrm{CCT}, \mathrm{V} 60>30 \%$ \\
\hline Present study & $\begin{array}{l}40-67 \mathrm{~Gy} \text { (median, } 60 \mathrm{~Gy} \text { ) } \\
\text { Single daily fractions of } 1.8 \text { or } 2 \mathrm{~Gy}\end{array}$ & Grade $1-2^{*}$ & $\mathrm{~V} 35>30 \%$ \\
\hline
\end{tabular}

CCT, Concurrent chemotherapy; RT, radiotherapy; LETT45, the length of esophagus (total circumference) treated with $>45 \mathrm{~Gy}$; A55, esophageal surface area $\left(\mathrm{cm}^{2}\right)$ receiving at least $55 \mathrm{~Gy}$; BMI, body mass index.

* Radiation Therapy Oncology Group scoring criteria for acute esophageal toxicity.

${ }^{\dagger}$ Modified from National Institutes of Health Common Toxicity Criteria, version 2.0.

than that of severe esophagitis (Werner-Wasik et al. 2000; Ahn et al. 2005). Werner-Wasik et al. (2000) noted 54 patients with RTOG grade 1 esophagitis in their 105 patient series; likewise, Ahn et al. (2005) reported 138 patients with AET of RTOG Grade 1 in their 254 patient series. Therefore, we believe that our result about AET of RTOG grade 2 or less has significance, though it may not be fatal. In the present study, we did not observe any cases of severe AET of RTOG grade 3 or worse, as was the case in our prior report (Takeda et al. 2005). One reason for this may have been that our prescribed doses are lower than those in other studies (Singh et al. 2003;
Bradley et al. 2004; Patel et al. 2004; Ahn et al. 2005), or that our study did not use TRT with BID fractionation (Werner-Wasik et al. 2000; Ahn et al. 2005). Another reason may be that concurrent chemotherapy was given consistently in other studies and, therefore, resulted in higher toxicity (Hirota et al. 2001a; Kim et al. 2005).

Although previous authors have noted significant correlations between concurrent chemotherapy and AET in lung cancer treatment (Werner-Wasik et al. 2000; Singh et al. 2003; Bradley et al. 2004; Kim et al. 2005), we did not find a statistically significant relationship between AET and chemotherapy, probably due to the in- 
homogeneity of our patients' disease and their treatments, which included various chemotherapeutic regimens, thus lessening the significance of any correlation. Furthermore, as this was a retrospective study, the chemotherapy was not randomly assigned.

In conclusion, the present study has demonstrated that V10-V55 and Dmean are significant parameters associated with mild AET. V35 > $30 \%$ appears to be the most critical factor in patients with intra-thoracic malignancies in TRT. Our findings provide new information about AET, and might be useful in designing a treatment plan to prevent severer esophageal toxicity.

\section{References}

Ahn, S.J., Kahn, D., Zhou, S., Yu, X., Hollis, D., Shafman, T.D. \& Marks, L.B. (2005) Dosimetric and clinical predictors for radiation-induced esophageal injury. Int. J. Radiat. Oncol. Biol. Phys., 61, 335-347.

Bradley, J., Deasy, J.O., Bentzen, S. \& El-Naqa, I. (2004) Dosimetric correlates for acute esophagitis in patients treated with radiotherapy for lung carcinoma. Int. J. Radiat. Oncol. Biol. Phys., 58, 1106-1113.

Bruner, D.W., Movsas, B., Konski, A., Roach, M., Bondy, M., Scarintino, C., Scott, C. \& Curran, W. (2004) Outcomes research in cancer clinical trial cooperative groups: the RTOG model. Qual. Life Res., 13, 1025-1041.

Byhardt, R.W., Scott, C., Sause, W.T., Emami, B., Komaki, R., Fisher, B., Lee, J.S. \& Lawton, C. (1998) Response, toxicity, failure patterns, and survival in five Radiation Therapy Oncology Group (RTOG) trials of sequential and/or concurrent chemotherapy and radiotherapy for locally advanced non-small-cell carcinoma of the lung. Int. J. Radiat. Oncol. Biol. Phys., 42, 469-478.

Chen, Y.Y., Huang, C.H., Tang, Y. \& Eng, H.L. (2004) Concurrent chemoradiotherapy for unresectable thymic carcinoma. Chang. Gung. Med. J., 27, 515-522.

Choy, H., LaPorte, K., Knill-Selby, E., Mohr, P. \& Shyr, Y. (1999) Esophagitis in combined modality therapy for locally advanced non-small cell lung cancer. Semin. Radiat. Oncol., 9, 90-96.

Clifford, Chao, K.S., Perez, C.A. \& Brady, L.W. (2002) Radiation Oncology, Management Decisions, 2nd ed., Williams \& Wilkins, Philadelphia, pp. 2-3.

Cox, J.D., Stez, J. \& Pajak, T.F. (1995) Toxicity criteria of the radiation therapy oncology group (RTOG) and the European organization for research and treatment of cancer (EOR-
TIC). Int. J. Radiat. Oncol. Biol. Phys., 31, 1341-1346.

Hirota, S., Tsujino, K., Endo, M., Kotani, Y., Satouchi, M., Kado, T., Hishikawa, Y., Obayashi, K., Takada, Y., Kono, M. \& Abe, M. (2001a) Dosimetric predictors of radiation esophagitis in patients treated for non-small-cell lung cancer with carboplatin/paclitaxel radiotherapy. Int. J. Radiat. Oncol. Biol. Phys., 51, 291-295.

Hirota, S., Tsujino, K., Hishikawa, Y., Watanabe, H., Kono, K., Soejima, T., Obayashi, K., Takada, Y., Kono, M. \& Abe, M. (2001b) Endoscopic findings of radiation esophagitis in concurrent chemoradiotherapy for intrathoracic malignancies. Radiother. Oncol., 58, 273-278.

International Commission on Radiation Units and Measurements (1993) ICRU Report No. 50. Prescribing, Recording, and Reporting Photon Beam Therapy. Bethesda, MD: International Commission on Radiation Units and Measurements, Washington, DC.

Kim, T.H., Cho, K.H., Pyo, H.R., Lee, J.S., Han, J.Y., Zo, J.I., Lee, J.M., Hong, E.K., Choi, I.J., Park, S.Y., Shin, K.H., Kim, D.Y. \& Kim, J.Y. (2005) Dose-volumetric parameters of acute esophageal toxicity in patients with lung cancer treated with three-dimensional conformal radiotherapy. Int. J. Radiat. Oncol. Biol. Phys., 62, 995-1002.

Masaoka, A., Monden, Y., Nakahara, K. \& Tanioka, T. (1981) Follow-up study of thymomas with special reference to their clinical stages. Cancer, 48, 2485-2492.

Patel, A.B., Edelman, M.J., Kwok, Y., Krasna, M.J. \& Suntharalingam, M. (2004) Predictors of acute esophagitis in patients with non-small-cell lung carcinoma treated with concurrent chemotherapy and hyperfractionated radiotherapy followed by surgery. Int. J. Radiat. Oncol. Biol. Phys., 60, 1106-1112.

Perez, R.A. \& Early, D.S. (2002) Endoscopy in patients receiving radiation therapy to the thorax. Dig. Dis. Sci., 47, 79-83.

Sailer, S.L. (2000) Three- dimensional conformal radiation therapy. In: Clinical radiation oncology, edited by L.L. Gunderson \& J.E. Tepper, Philadelphia, Churchill Livingstone, pp. 243-245.

Singh, A.K., Lockett, M.A. \& Bradley, J.D. (2003) Predictors of radiation-induced esophageal toxicity in patients with non-small-cell lung cancer treated with three-dimensional conformal radiotherapy. Int. J. Radiat. Oncol. Biol. Phys., 55, 337-341.

Takeda, K., Nemoto, K., Saito H., Ogawa, Y., Takai, Y. \& Yamada, S. (2005) Dosimetric correlations of acute esophagitis in lung cancer patients treated with radiotherapy. Int. J. Radiat. Oncol. Biol. Phys., 62, 626-629.

Werner-Wasik, M., Pequignot, E., Leeper, D., Hauck, W. \& Curran, W. (2000) Predictors of severe esophagitis include use of concurrent chemotherapy, but not the length of irradiated esophagus: a multivariate analysis of patients with lung cancer treated with nonoperative therapy. Int. J. Radiat. Oncol. Biol. Phys., 48, 689-696. 